\title{
FERRAMENTAS DE \\ EDUCOMUNICAÇÃO \\ SOCIOAMBIENTAL: SUBSÍDIOS \\ PARA A GESTÃO INTEGRADA \\ DA ZONA COSTEIRA
}

\author{
Vanessa Caetano Marques ${ }^{1}$ \\ João Luiz Nicolodi ${ }^{2}$
}

Resumo: A Gestão Costeira Integrada (GCl) pressupõe a difusão de informações e capacitação de atores sociais visando à participação efetiva neste processo. No âmbito da Política Nacional de Educação Ambiental (PNEA), o Programa Nacional de Educomunicação Socioambiental aporta subsídios para produção da informação, difusão e acesso democrático. Este trabalho apresenta o processo de criação de material audiovisual sobre temáticas da $\mathrm{GCl}$ e analisa suas potencialidades sob a ótica do percurso formativo da Educação Ambiental (EA) e da compatibilidade com os princípios da Educomunicação Socioambiental. Os resultados demonstram que essa compatibilidade é positiva, bem como permitem inferir que o mesmo tem potencial para auxiliar no fortalecimento dos indicadores de maturidade e eficácia da $\mathrm{GCl}$, uma vez estar embasado na integração de distintas políticas públicas, seguindo estruturas normativas etjá existentes e incorporando a participação do órgão competente pela gestão costeira do país.

Palavras-chave: Gestão Costeira; Educação Ambiental; Educomunicação Socioambiental.

\footnotetext{
${ }^{1}$ Universidade Federal de Santa Catarina. E-mail: vanessamarques.c@hotmail.com , Link para o Lattes: http://lattes.cnpq.br/4053840627571763

2Universidade Federal do Rio Grande. E-mail: joaonicolodi@furg.br, Link para o Lattes: http://lattes.cnpq.br/1779920673536937
} 
Abstract: The Integrated Coastal Management (ICM) requires the dissemination of information and the training of social actors for effective participation in this process. In the context of the National Environmental Education Policy the Socio-Environmental Educommunication Program provides subsidies for the production of information, dissemination and democratic access to citizens. This work is inserted in this context, presenting the process of creating audiovisual material on $\mathrm{GCl}$ themes and analyzing their potentialities from the perspective of the Environmental Education (EA) training path and compatibility with the principles of Socio-Environmental Educommunication. The results demonstrate that the analyzed material is compatible with such principles, as well as that it has the potential to help improve the maturity and effectiveness indicators of the $\mathrm{GCl}$, since it is based on the integration of different public policies, following existing normative structures and incorporating the participation of institutions responsible for the country's coastal management.

Keywords: Coastal Management; Environmental Education; Socioenvironmental Educommunication.

\section{Introdução}

O Gerenciamento Costeiro Integrado (GCl) caracteriza-se como um processo dinâmico, contínuo e interativo que tem a finalidade de promover o desenvolvimento sustentável das áreas litorais através da integração de políticas, objetivos, estratégias e planos setoriais no espaço e tempo (BARRAGÁN, 2003). Este processo de gestão pode contribuir à discussão sobre os Objetivos de Desenvolvimento Sustentável (ODS), com destaque para o ODS 14 - Conservação e uso sustentável dos oceanos, dos mares e dos recursos marinhos para o desenvolvimento sustentável (ONU, 2015).

O Brasil tornou-se signatário deste plano e, invariavelmente, para que o país caminhe em direção ao ODS 14 é preciso que boas práticas de gestão costeira sejam desenvolvidas, como por exemplo, àquelas que abordam a capacitação da participação social no processo de $\mathrm{GCl}$ e, principalmente, nas tomadas de decisões (ROCKLOFF; LOCKIE, 2004; SCHIVELY, 2007). A literatura especializada, como Souza (2001), Milani (2008), Moraes et al. (2010), Andrade e Scherer (2014) e Nicolodi et al. (2018; 2021) evidenciam a deficiência da participação da sociedade no processo, seja por ser inexistente ou por ser incapacitada, ao mesmo tempo que aponta a necessidade de que a gestão seja compartilhada e participativa para que apresente maior efetividade (BARRAGÁN, 2003; 2010; 2016).

As diretrizes para o desenvolvimento dessas práticas já são previstas no arcabouço legal das políticas públicas brasileiras, como na Política Nacional 
de Meio Ambiente (PNMA) ${ }^{3}$, no Plano Nacional de Gerenciamento Costeiro $(P N G C)^{4}$ e na Política Nacional de Educação Ambiental (PNEA) ${ }^{5}$, e também, no Programa Nacional de Educomunicação Socioambiental, criado como uma linha de ação dentro do Programa Nacional de Educação Ambiental (ProNEA).

Sob a ótica legal, a Educomunicação é considerada como campo de intervenção social que visa promover o acesso democrático dos cidadãos à produção e à difusão da informação, envolvendo a ação comunicativa no espaço educativo formal ou não formal, cuja aplicação foi oficializada através de resolução do Conselho Nacional do Meio Ambiente (CONAMA) ${ }^{6}$.

Como um campo da ciência a Educomunicação é tida fundamentalmente como uma ação política (SOARES, 2011) e como uma ferramenta de comunicação para ações educacionais. Tassara (2008) a definiu como um processo de comunicação com intencionalidade educacional expressa e que envolve a democratização da produção e de gestão da informação nos meios de comunicação em seus diversos formatos, ou na comunicação presencial.

De acordo com Kaplún (1998), a Educomunicação é uma área do conhecimento que aponta para a prática da leitura crítica dos meios e é pautada por princípios próprios (COSTA, 2008), os quais consideram a indissociabilidade entre questões sociais e ambientais no fazer-pensar dos atos educativos e comunicativos é ressaltada pelo termo socioambiental (SOARES, 2011).

Através da construção de materiais educativos vinculados ao desenvolvimento da cidadania e a consequente capacitação dos atores sociais, a Gestão Costeira - da mesma forma que a Gestão Ambiental (QUINTAS; GUALDA, 1995), incorpora as ações de EA e de Educom como ferramentas para a estruturação dos atores sociais e a qualificação da participação organizada no processo de $\mathrm{GCl}$ como um todo.

Sob essa ótica, em 2016, o Ministério do Meio Ambiente (MMA) avançou na formulação de estratégias de capacitação e desenvolvimento de material compatível sobre a Zona Costeira brasileira. Com base nessa demanda, foi estabelecida uma parceria entre MMA e a Universidade Federal do Rio Grande (FURG), na qual foi concebido um projeto para elaboração de um conjunto de quatro vídeos e quatro cartilhas digitais de cunho informativo ${ }^{7}$ com potencial para serem utilizadas em ações de Educação Ambiental formal e/ou não formal.

Nesse contexto, a presente pesquisa tem como objetivo apresentar o processo de desenvolvimento dos roteiros metodológicos para a elaboração

\footnotetext{
${ }^{3}$ Lei Federal no 9638/1988

${ }^{4}$ Lei Federal ํㅜ 7661/1988

${ }^{5}$ Lei Federal ํㅜ 9795/1999

${ }^{6}$ Resolução no $422 / 2010$

${ }^{7}$ https://gaigerco.furg.br/produtos/2-uncategorised/28-produtos-videos-cartilhas
} 
dos dois primeiros vídeos supracitados, juntamente com a análise das potencialidades dos mesmos sob a ótica do percurso formativo da Educação Ambiental (EA) para formação de sujeitos EA e com o estudo da compatibilidade do material produzido com os princípios da Educomunicação Socioambiental.

\section{Metodologia}

Os roteiros metodológicos, primordialmente, dizem respeito à transposição de informações socioambientais científicas, técnicas e legais sobre a gestão costeira para materiais de cunho educativo por meio de uma linguagem didática e concisa, capaz de comunicar diferentes segmentos sociais e culturais.

Para tanto, foi aplicada a metodologia proposta de Investigação e Redução Temáticas (FREIRE, 1975; SNYDERS, 1988). Tal método é caracterizado por quatro etapas descritas na Tabela 1.

Tabela 1: Etapas dos processos de Investigação e Redução Temáticas.

\begin{tabular}{|c|c|}
\hline ETAPA & DESCRIÇÃO \\
\hline 1 & $\begin{array}{l}\text { Levantamento preliminar: constitui o recolhimento de dados e informações } \\
\text { secundárias a partir de documentos obtidos em órgãos governamentais e outras } \\
\text { instituições sociais. Sob a ótica escolar, dizem respeito à pesquisa sobre as } \\
\text { condições locais em que vivem os alunos e seus familiares, que juntamente com } \\
\text { entrevistas com representantes, lideranças locais e os pais de alunos são fontes de } \\
\text { aproximação da realidade deles. }\end{array}$ \\
\hline 2 & $\begin{array}{l}\text { Temas geradores: depois da análise das informações apreendidas com a etapa } \\
\text { anterior, é feita a escolha de situações que apresentem contradições a serem } \\
\text { compreendidas pelos envolvidos no processo educativo; }\end{array}$ \\
\hline 3 & $\begin{array}{l}\text { Círculo de investigação temática: as situações escolhidas na segunda etapa são, } \\
\text { primeiramente, apostas ou hipóteses que os educadores/pesquisadores fazem } \\
\text { baseados no conteúdo da primeira etapa. Mas que só se confirmarão nessa terceira } \\
\text { etapa, onde são realizadas reuniões também com pais de alunos e outros } \\
\text { representantes da comunidade no intuito de validar a significância dos temas } \\
\text { geradores para o coletivo; }\end{array}$ \\
\hline
\end{tabular}

4 Redução Temática: na quarta etapa, com os resultados que vão sendo obtidos, realiza-se a elaboração do programa e do planejamento de ensino.

Fonte: Adaptado de Delizoicov et al. (2002).

Foram aplicadas algumas adaptações metodológicas ao método de Delizoicov et al. (2002), uma vez que o material analisado é de cunho informal, podendo ser utilizado em ações de Educação Ambiental tanto em ambiente escolar quanto nos diversos espaços da sociedade, concedendo-lhe um caráter formal e/ou não formal. Além disso, a equipe do projeto também difere do viés tradicional dos ambientes formais de educação, incluindo professores, 
pesquisadores, gestores públicos e uma equipe de arte aplicada, fato este que contribui para uma pluralidade mais acentuada de ideias e valores discutidos.

Foram estipuladas quatro etapas metodológicas de investigação e redução temáticas, as quais demandaram um encadeamento lógico que pode ser observado na Figura 1, assim como a descrição destas etapas.

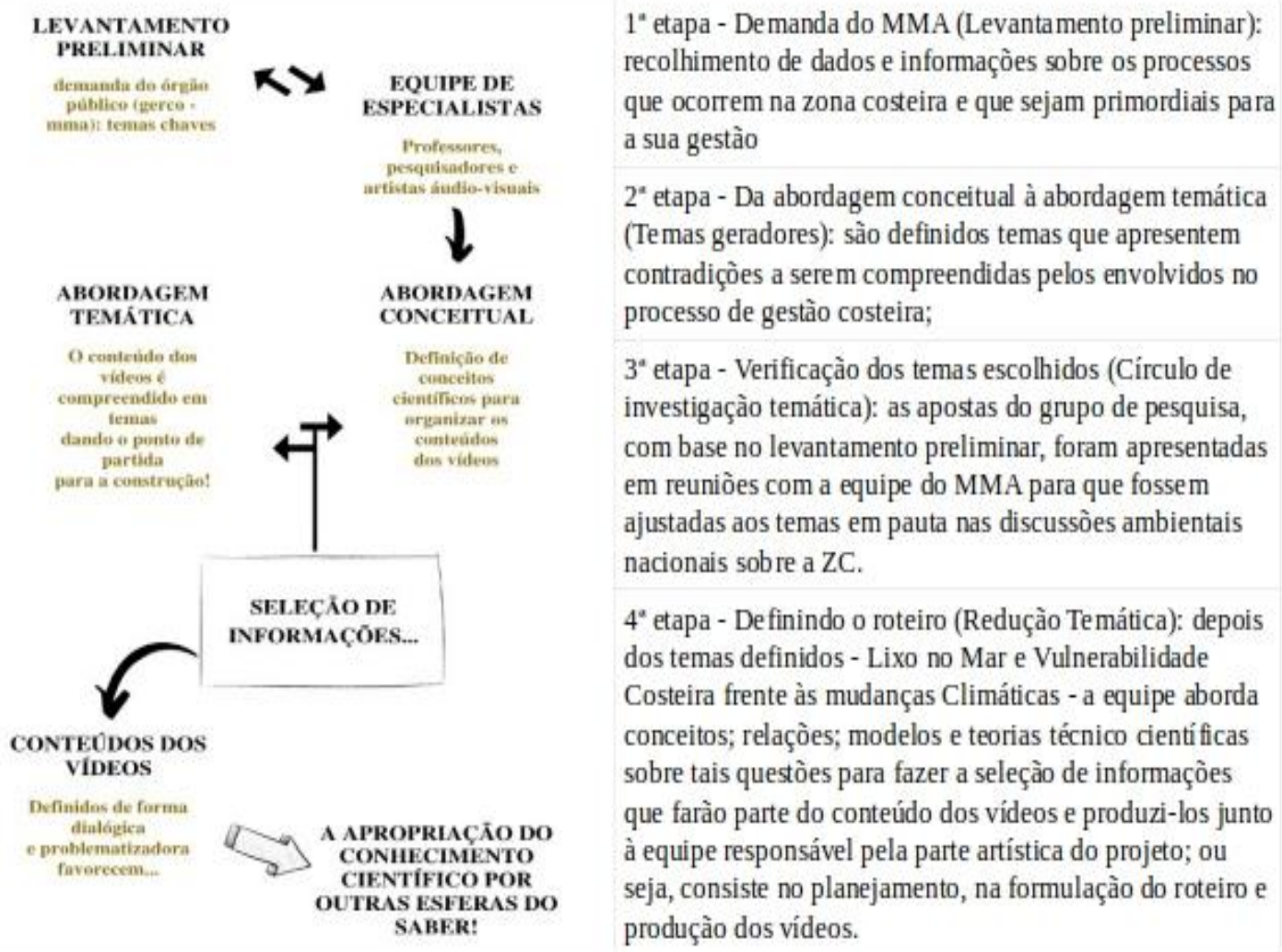

Figura 1: Etapas metodológicas de investigação e redução temáticas adaptadas.

Fonte: Os autores.

Do ponto de vista do tipo de linguagem pedagógica, foi adotada a Taxonomia de Bloom (BLOOM et al., 1956), uma vez permitir a identificação de objetivos ligados ao desenvolvimento cognitivo e facilitar o planejamento do processo de ensino e aprendizagem (TANNER, 1978; MANDEL, 1992; ANDERSON et al., 2001). Outro aspecto relevante na produção do material relaciona-se com as especificações do público-alvo, o qual foi definido para indivíduos com faixa etária acima de quatorze anos e com nível de instrução compatível à idade.

A construção dos roteiros metodológicos foi dividida em dois segmentos, denominados de roteiro técnico e roteiro artístico, no qual as informações técnico-científicas foram selecionadas e agrupadas de forma a obter uma sequência de fenômenos interligados possíveis de serem contados através de uma estória. 
Como forma de avaliação dos produtos, foram aplicados questionários compostos por cinco questões objetivas, sendo quatro binárias (resposta positiva ou negativa) e uma questão de múltipla escolha (Tabela 2). A aplicação dos questionários se deu com o lançamento oficial do vídeo 'Um Mar de Lixo' durante $1^{\circ}$ Seminário Nacional sobre o combate ao Lixo no Mar, realizado em 2017, e teve como objetivo captar a opinião de um grupo de especialistas sobre a efetividade e capacidade educativo-informativa do vídeo sobre os temas abordados. Ademais, os questionados contaram com um espaço livre para que os entrevistados pudessem deixar suas contribuições sobre o material exposto.

Tabela 2: Questões para investigação das potencialidades do material informativo-educacional para a formação de sujeitos EA.

\section{QUESTÕES SOBRE O POTENCIAL EDUCATIVO DOS VÍDEOS. EXEMPLO: VÍDEO “UM MAR DE LIXO"}

1 Você acha este vídeo apto para informar e/ou educar os cidadãos sobre a problemática do lixo marinho?

2 Caso você tenha envolvimento com a capacitação de atores sociais, você o utilizaria em ações educativas e em capacitações dos mesmos?

3 Você acha que este tipo de abordagem (lúdica/animação) pode contribuir com uma maior sensibilização da sociedade sobre o tema em questão?

4 Em sua opinião, o material conseguiu transpor os conhecimentos técnicos sobre o tema de forma satisfatória neste tipo de linguagem?

5 Defina como você se sentiu após assistir ao vídeo: a. triste, b. feliz, c. revoltado, d. esperançoso, e. desanimado, f. indiferente, e, g. outros.

Fonte: Os autores.

Visando aferir a potencialidade do material produzido na formação de cidadãos ambientais foi aplicada a metodologia do Percurso Formativo do sujeito EA (KITZMANN, 2015). Intimamente ligado ao exercício da aprendizagem em escala individual e coletiva, este arranjo retrata etapas crescentes, expostas na Tabela 3, do desenvolvimento da constituição de sujeitos capazes de participarem de modo qualificado nos processos de tomada de decisão a partir do qual é possível identificar as potencialidades das ações de EA, bem como direcionar a formulação das ações de acordo com os seus objetivos.

$8<$ https://antigo.mma.gov.br/gestao-territorial/gerenciamento-costeiro/zona-costeira-eoceanos/item/15418-semin\%C3\%A1rio-nacional-sobre-combate-ao-lixo-no-mar.html> 
Tabela 3: Etapas do Percurso Formativo do sujeito EA.

\section{ETAPAS DO PERCURSO FORMATIVO DO SUJEITO EA}

1 Sensibilização Ambiental: processo de alerta, considerado como primeiro objetivo para alcançar o pensamento sistêmico da EA;

2 Compreensão ambiental: conhecimento dos componentes e dos mecanismos que regem o sistema natural;

3 Responsabilidade ambiental: reconhecimento do ser humano como principal protagonista para determinar e garantir a manutenção do planeta;

4 Competência ambiental: capacidade de avaliar e agir efetivamente no sistema ambiental;

5 Cidadania ambiental: capacidade de participar ativamente, resgatando os direitos e promovendo uma nova ética capaz de conciliar a natureza e a sociedade.

Fonte: Kitzmann (2015).

\section{Resultados e Discussões}

Os conceitos técnico-científicos articulados na composição do tema 'Lixo no Mar', (primeiro vídeo produzido ${ }^{9}$ ), em conjunto com as respectivas referências, são expostos na Tabela 4.

Tabela 4: Roteiro técnico para a produção do vídeo 'Um Mar de Lixo'.

\begin{tabular}{ll}
\hline \multicolumn{1}{c}{ ROTEIRO TÉCNICO - CONCEITOS TÉCNICO-CIENTíFICOS CONTIDOS NO VÍDEO } \\
'UM MAR DE LIXO
\end{tabular}

Panorama legal sobre os PNRS-Brasil (2010) resíduos sólidos no Brasil

Fonte: os autores.

9 https://www.youtube.com/watch?v=L5B5zDM mDc\&t=1s 
Composto pela estória que conterá as informações selecionadas desse aparato de conceitos, o roteiro artístico foi desenvolvido considerando a preocupação com a representatividade dos personagens (gênero, cor etc.), mas sem desprezar as simbologias inerentes aos temas trabalhados. Optou-se por criar um personagem inspirado em Jacques-Yves Cousteau, um símbolo da Oceanografia, para o narrador/personagem. A Tabela 5 apresenta a estrutura do roteiro artístico e exemplos de sua composição visual. A estrutura da narrativa criada e as questões a ela incorporadas podem ser observadas na Tabela 6.

Tabela 5: Estrutura do roteiro artístico e composição visual do vídeo 'Um Mar de Lixo'.

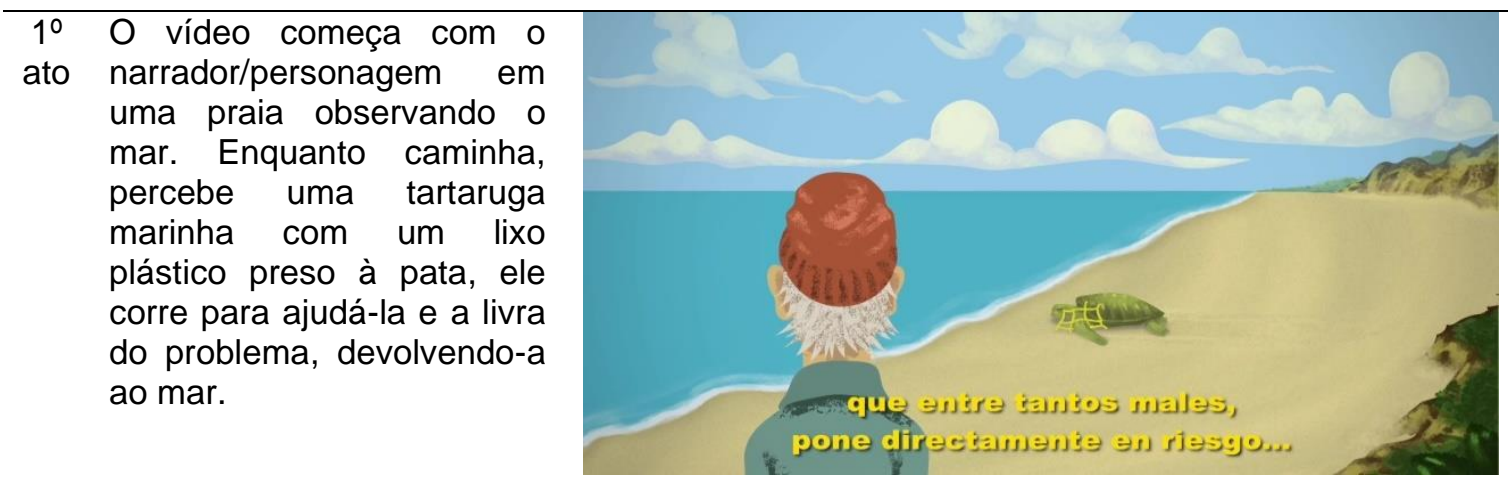

\begin{tabular}{ll}
\hline $2^{\circ}$ & O narrador inicia a \\
ato explanação do conteúdo & \\
analisando as origens, \\
impactos e diretrizes sobre \\
o tema do lixo no mar no \\
Brasil (PNRS).
\end{tabular}

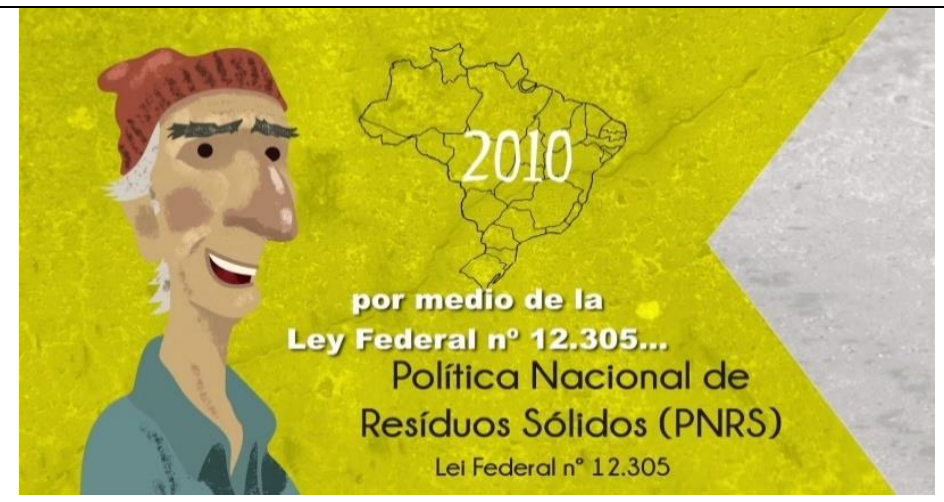

\begin{aligned} & \hline $3^{\circ} \mathrm{Na}$ conclusão do vídeo, \\ & ato $\begin{array}{l}\text { temos } \\ \text { abordando } \mathrm{narrador} \\ \text { individuais positivas para }\end{array} \\ &$ minimizar o problema do \\ & lixo no mar e vemos \\ & novamente a tartaruga do \\ & início do vídeo, nadando em \\ & alto mar rumo ao horizonte. \end{aligned}

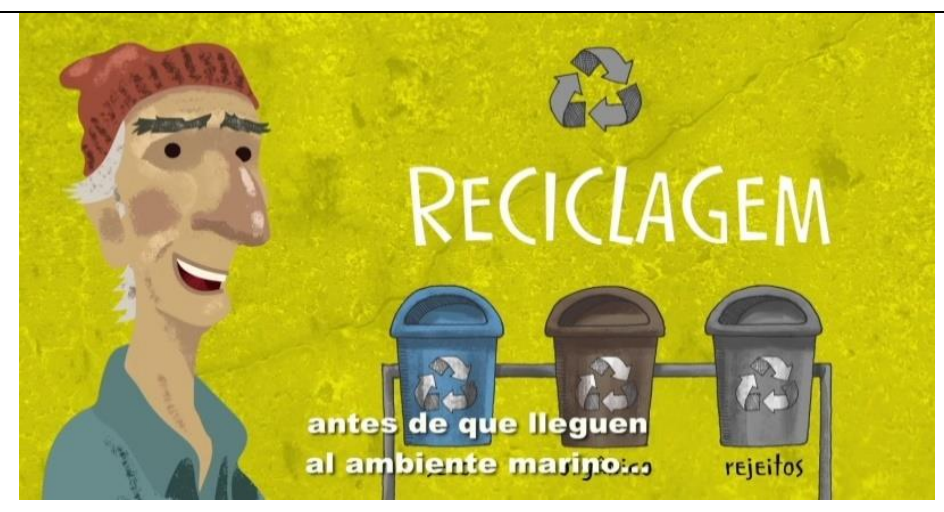

Fonte: os autores. 
Tabela 6: Roteiro artístico para a produção do vídeo 'Um Mar de Lixo'.

\begin{tabular}{ll}
\hline QUESTÕES ABORDADAS AO LONGO DA NARRATIVA NO VÍDEO ‘UM MAR DE LIXO' \\
\hline 1 & Breve introdução aos oceanos, sua relevância e suas pressões antrópicas \\
\hline 2 & Você sabe o que é lixo marinho? \\
\hline 3 & Quais as origens do lixo marinho? \\
\hline 4 & Para onde esse lixo vai? \\
\hline 5 & Quais são os impactos do lixo marinho? \\
\hline 6 & Qual o panorama do lixo marinho no Brasil? \\
\hline 7 & Como você pode contribuir? \\
\hline 8 & Conclusão \\
\hline
\end{tabular}

Fonte: os autores.

Já em relação ao segundo vídeo, 'Um Mar de Ameaças'10, os conceitos técnico-científicos, bem como suas referências, utilizados na composição do tema 'Vulnerabilidade Costeira frente às Mudanças Climáticas' podem ser observados na Tabela 7.

Tabela 7: Roteiro técnico para a produção do vídeo 'Um Mar de Ameaças'.

ROTEIRO TÉCNICO - CONCEITOS TÉCNICO-CIENTÍFICOS CONTIDOS NO VÍDEO ‘UM MAR DE AMEAÇAS'

Conceitos

Referências

Tectônica de placas e a atual Castello \& Krug (2015)

configuração das Zonas Costeiras

Mudanças Climáticas $\quad$ Skinner \& Porter (2004), Carter (2007), Sabedot (2008), IPCC, (2018), Tol (2018), Watts et al. (2015).

Ocupação e uso do espaço Nascimento \& Lima (2010), Nakano (2006), Stroheaker costeiro (2008), Castello \& Krug (2015), Nicolodi et al. (2021).

Vulnerabilidade Costeira e Riscos Nicolodi \& Petermann (2011), Santos et al. (2015), Costeiros Marengo et al. (2016), Asmus et al. (2019)

Zona de Não Edificação (Zona de Muehe (2011)

Recuo)

Panorama legal sobre as Plano Nacional sobre Mudanças do Clima (PNMC) mudanças climáticas (2008), Plano Nacional de Adaptação à Mudança do Clima (PNA) (2016)

Fonte: os autores.

Baseado no aparato das informações técnico-científicas contidas no roteiro técnico foi desenvolvido o roteiro artístico para transpor tais informações a uma linguagem mais difusa e lúdica através da estória que segue (Tabela 8). Neste caso, o personagem do primeiro vídeo foi mantido e foram acrescentados personagens novos que remetem à heterogeneidade social presente na formação brasileira, misturando gênero, idade e cor.

$10<$ https://www.youtube.com/watch?v= b6uxHQUAdE $>$

Revbea, São Paulo, V. 16, № 2: 385-408, 2021. 
Tabela 8: Estrutura do roteiro artístico e composição visual do vídeo 'Um mar de ameaças'.

\begin{tabular}{|c|c|c|}
\hline & $\begin{array}{l}\text { O vídeo tem início com } \\
\text { o narrador apresentando } \\
\text { a estória de uma família } \\
\text { constituinte de uma } \\
\text { comunidade costeira, a } \\
\text { qual estabeleceu sua } \\
\text { vida; ao longo das } \\
\text { gerações à beira mar. A } \\
\text { família, comandada pela } \\
\text { matriarca Dona } \\
\text { Francisca e cuja fonte } \\
\text { de renda vem da venda } \\
\text { de quitutes em seu } \\
\text { quiosque na praia desde } \\
\text { o final dos anos } 70 \text {, vê } \\
\text { sua vida mudar com a } \\
\text { expansão imobiliária e a } \\
\text { urbanização da orla } \\
\text { marítima do lugar. }\end{array}$ & (1) \\
\hline & $\begin{array}{l}\text { O narrador inicia a } \\
\text { explanação do conteúdo } \\
\text { analisando o conceito } \\
\text { de vulnerabilidade } \\
\text { costeira; suas causas e } \\
\text { consequências, } \\
\text { utilizando o exemplo da } \\
\text { família de Dona } \\
\text { Francisca, bem como as } \\
\text { iniciativas legais que } \\
\text { Estado brasileiro prevê } \\
\text { para lidar com essas } \\
\text { situações de } \\
\text { vulnerabilidade costeira. }\end{array}$ & \\
\hline & $\begin{array}{l}\text { O vídeo é concluído } \\
\text { com a mudança da } \\
\text { família para uma praia } \\
\text { onde a GC seja } \\
\text { realmente efetiva, com o } \\
\text { planejamento } \\
\text { urbanístico e costeiro } \\
\text { integrados às diretrizes } \\
\text { do projeto ORLA. } \\
\text { Também são abordados } \\
\text { conceitos básicos para a } \\
\text { prática de boas ações } \\
\text { de gestão costeira, } \\
\text { como o de zona de } \\
\text { recuo ou zona de não } \\
\text { edificacaão. }\end{array}$ & $\begin{array}{l}\text { El primer paso fue elegir una región-con } \\
\text { planifficación urbanistica y costera eficiente... }\end{array}$ \\
\hline
\end{tabular}

Fonte: os autores. 
Tabela 9: Roteiro artístico para a produção do vídeo 'Um Mar de Ameaças'.

\section{QUESTÕES ABORDADAS AO LONGO DA NARRATIVA NO VÍDEO 'UM MAR DE}

AMEAÇAS'

1 Breve apresentação da estória de uma família brasileira tradicional costeira, a qual vive à beira mar e sobrevive dele, mas que com o passar do tempo e das modificações na orla, encontra-se vulnerável.

2 O que é e quais são as causas e consequências da vulnerabilidade costeira?

3 Quais as iniciativas do Brasil diante das vulnerabilidades costeiras?

4 Conclusão da narrativa com o desfecho da família e bons exemplos de uso e ocupação da zona costeira.

5 Conclusão

Fonte: os autores.

A premência da elaboração de materiais que venham a contribuir no processo educativo sobre as Mudanças Climáticas na Zona Costeira do Brasil foi atestada por Quintana e Kitzmann (2020), os quais, por meio de pesquisa qualitativa documental realizada a partir do marco legal nacional sobre Educação Ambiental (EA) e Mudanças Climáticas, concluíram que a presença da EA nas políticas públicas sobre Mudanças Climáticas na Zona Costeira é incipiente, tornando-se necessário avançar no planejamento dos processos educativos emancipatórios direcionados à temática.

De forma a subsidiar a investigação acerca das potencialidades de uso do material produzido sob a ótica do percurso formativo de sujeitos EA, foram aplicados questionários (específicos sobre o vídeo "Um mar de lixo") durante o 10 Seminário Nacional de combate ao Lixo no Mar e respondidos por um público composto por 56 indivíduos de diferentes formações profissionais (Figura 2).

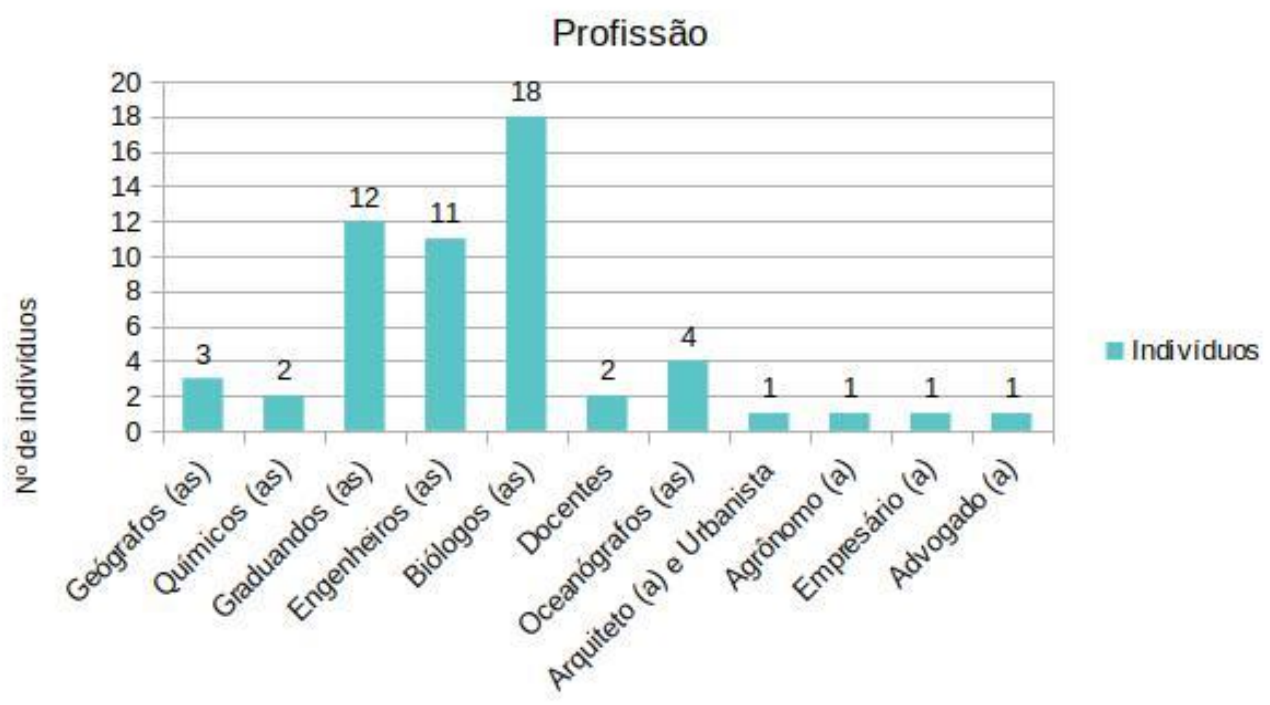

Figura 2: Formação profissional dos questionados.

Fonte: os autores. 
Percebe-se que a amostra de indivíduos é, supostamente, bastante esclarecida sobre as questões ambientais. O universo amostral da pesquisa é composto majoritariamente por Biólogos (32,14\%), seguido de estudantes do ensino superior $(21,43 \%)$, Engenheiros Ambientais; Químicos, Sanitaristas, Agrônomos e de Pesca (19,64\%), Oceanógrafos (7,14\%), Geógrafos (5,36\%), Químicos e Docentes (3,57\%), Arquiteto e Urbanista (1,78\%), Agrônomo $(1,78 \%)$, Empresário (1,78\%) e Advogado (1,78\%). Tais atores atuam de formas distintas socialmente, conforme pode ser observado no gráfico da Figura 3.

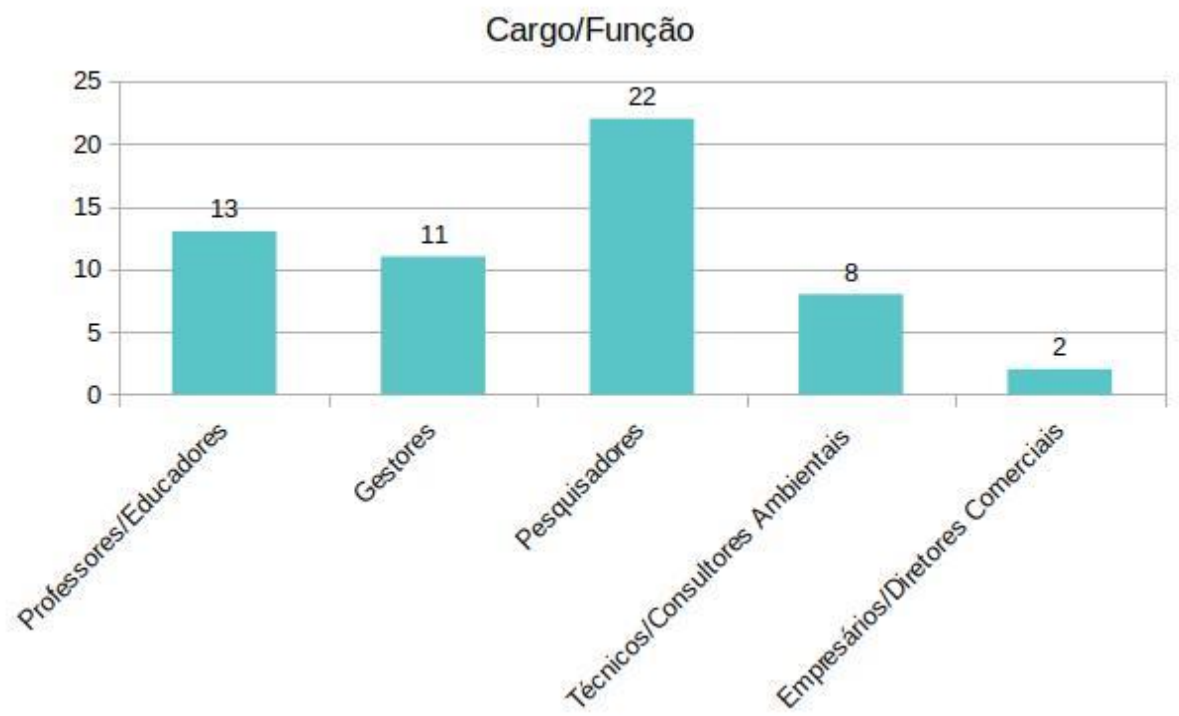

Figura 3: Cargo ou Função dos questionados.

Fonte: os autores

Em sua maioria, os profissionais entrevistados atuam socialmente como Pesquisadores (39,29\%), em seguida destacam-se Professores e lou Educadores (23,22\%), Gestores (19,64), Analistas; Técnicos e Consultores Ambientais (14,28\%); e por fim, Empresários e Diretores Comerciais (3,57\%).

As questões que compõem o escopo do questionário são apresentadas a seguir, nas Figuras 4 e 5 , em conjunto com os gráficos referentes às respostas das mesmas. 

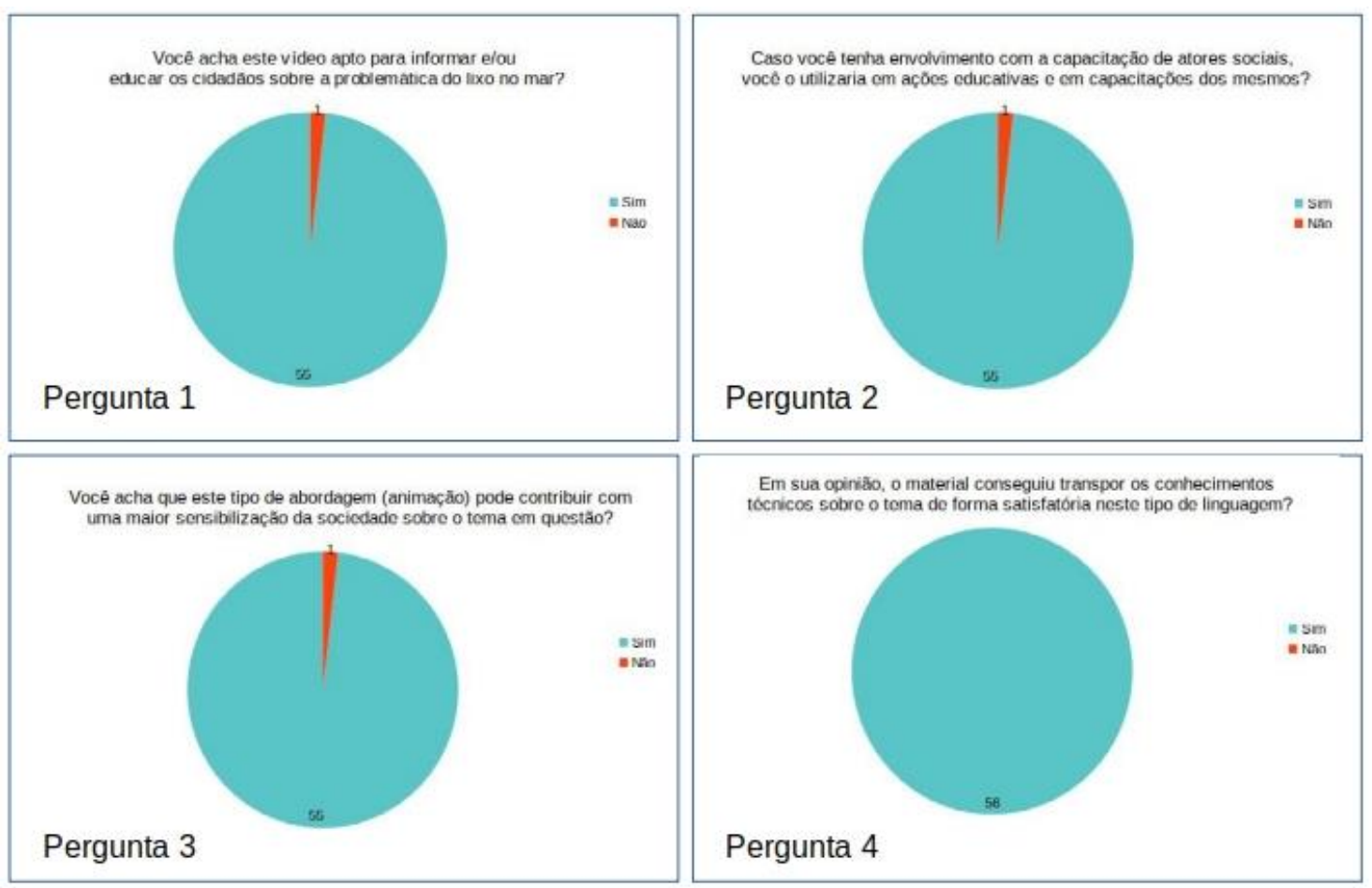

Figura 4: Gráficos referentes às quatro primeiras questões do questionário.

Fonte: os autores.

A primeira questão, acerca da aptidão do material demonstrou que 55 das $56(98 \%)$ respostas foram positivas, ou seja, a quase totalidade de entrevistados considerou o vídeo apto para informar e/ou educar os cidadãos sobre a problemática do lixo no mar. Dentre as considerações foram apontadas: a linguagem adequada, a boa didática, objetividade e boa seleção de conteúdo. Por outro lado, houve também considerações sobre a falta de enfoque na diminuição do consumo, o que justificou o resultado negativo de $2 \%$ (1/56 respostas).

Os resultados da segunda questão (aplicabilidade do conteúdo) foram semelhantes aos da pergunta anterior, com 98\% das respostas positivas (os sujeitos utilizariam o material em ações educativas e em capacitações), enquanto que $2 \%$ foram negativas (não utilizariam). Tal fato aponta a utilização do material como uma ferramenta de apoio para ações de EA e capacitações na formação continuada de atores sociais, bem como para motivar discussões em grupo e sistematizar o pensamento antes da instrução formal. Foi apontada também a importância da diversidade de estratégias pedagógicas em abordar os conteúdos, pois a amplitude do entendimento aumenta a eficácia do processo de mudança de hábitos; valores e metas. No que diz respeito à resposta negativa, a justificativa também remete a questão anterior; pelo fato de não estimular a reflexão dos hábitos de consumo e de sua redução.

Referente à pergunta 3 (linguagem de animação) os mesmos números foram obtidos, onde para $98 \%$ dos indivíduos a adoção desse tipo de 
abordagem pode contribuir com uma maior sensibilização social. Os respondentes consideraram que na atual sociedade digital esses métodos podem aumentar a motivação para discutir e buscar soluções para o problema, bem como para a mudança de hábitos e valores. Já para a parte que compõe a resposta negativa, foi apontada a significância de apresentar o personagem principal como agente e não como narrador apenas, pois isso criaria uma identificação maior por parte de quem assiste e poderia contribuir com o processo de sensibilização social.

Em relação à competência do vídeo em transpor os conhecimentos técnicos sobre o tema (pergunta 4), 100\% dos respondentes afirmaram que tal transposição foi feita de forma satisfatória. Os apontamentos refletem a possibilidade de melhoramento do conteúdo em relação à amplitude do tema tratado, bem como a utilização de alguns termos técnicos que poderiam ser revistos, mas também apontam a linguagem utilizada como de fácil entendimento para diversos atores sociais.

Por fim, no que confere às sensações provocadas ao final do vídeo conteúdo da quinta questão (Figura 5) - 34\% dos indivíduos sentiram-se esperançosos, $29 \%$ apontaram outros sentimentos ou um misto deles, satisfeito, preocupado, informado e esclarecido. Ademais, $14 \%$ sentiram-se triste, $4,7 \%$ feliz; revoltado e desanimado, e apenas $2 \%$ sentiu-se indiferente (por pesquisar a temática há muito tempo, os sentimentos envolvidos são anteriores ao vídeo).

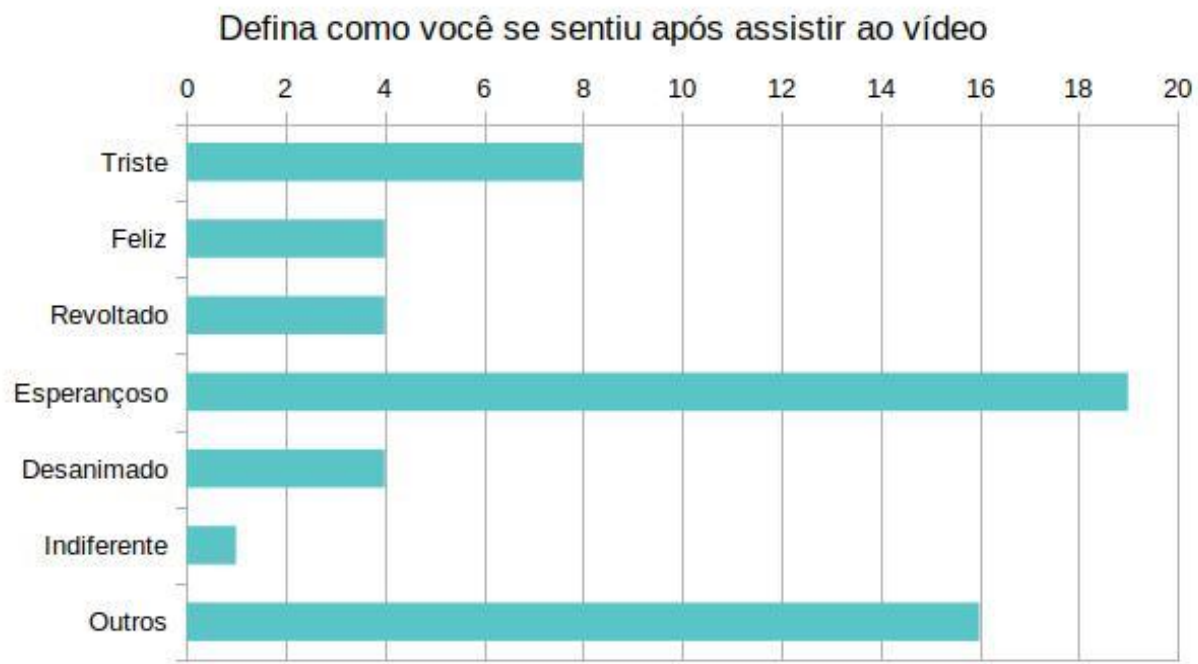

Figura 5: Histograma referente à última questão do questionário.

Fonte: os autores.

Correlacionando o conteúdo dos questionários com as etapas do Percurso Formativo de sujeitos EA, torna-se possível indicar potencialidades de uso do material na formação dos mesmos, no que compete cada etapa do percurso. Esta análise encontra-se sistematizada no quadro da Tabela 10. 
Tabela 10. Análise dos vídeos com base no Percurso Formativo de sujeitos EA.

\begin{tabular}{|c|c|}
\hline $\begin{array}{l}\text { Etapa do Percurso } \\
\text { Formativo de } \\
\text { sujeitos EA }\end{array}$ & Análise \\
\hline $\begin{array}{c}\text { Sensibilização } \\
\text { Ambiental }\end{array}$ & $\begin{array}{l}\text { O material possui a capacidade de promover esse processo de } \\
\text { alerta na medida em que explica com clareza o tema abordado, } \\
\text { mostrando todos os atores sociais envolvidos na questão; bem } \\
\text { como suas responsabilidades, mesmo que superficialmente. } \\
\text { Dessa forma, é capaz de proporcionar uma concepção mais } \\
\text { ampla sobre o assunto e o repensar de atitudes cotidianas, } \\
\text { como o descarte correto dos resíduos, o consumo mais } \\
\text { consciente e a cobrança de ações dos órgãos de gestão sobre } \\
\text { o tratamento dos resíduos. }\end{array}$ \\
\hline $\begin{array}{l}\text { Compreensão } \\
\text { ambiental }\end{array}$ & $\begin{array}{l}\text { No que diz respeito ao conhecimento dos componentes e dos } \\
\text { mecanismos que regem o sistema natural, o vídeo aponta o } \\
\text { comportamento do ambiente marinho diante da problemática } \\
\text { ao elucidar a imersão e submersão dos resíduos; os } \\
\text { mecanismos das correntes oceânicas que dispersam e/ou } \\
\text { acumulam tais resíduos e a vida marinha afetada por eles. }\end{array}$ \\
\hline $\begin{array}{c}\text { Responsabilidade } \\
\text { ambiental }\end{array}$ & $\begin{array}{l}\text { O material apresenta-se apto, na medida em que aborda o ser } \\
\text { humano como o agente causador do problema do lixo no mar, } \\
\text { o material possibilita o espectador a se colocar como } \\
\text { protagonista da situação, podendo promover reflexões acerca } \\
\text { de suas próprias atitudes que contribuem com a problemática e } \\
\text { a possível mudança de atitude. }\end{array}$ \\
\hline $\begin{array}{l}\text { Competência } \\
\text { ambiental }\end{array}$ & $\begin{array}{l}\text { Permite uma avaliação geral sobre o assunto abordado, como: } \\
\text { o que é; de onde vem e para onde vai; como afeta o ambiente } \\
\text { como um todo; de quem são as responsabilidades e o que } \\
\text { podemos fazer a respeito, estando apto a promover novas } \\
\text { formas de agir com base nessas informações apresentadas. } \\
\text { Dessa forma, contribui não só com a avaliação do problema, } \\
\text { mas também com auto avaliação por parte de quem o assiste e } \\
\text { a partir disso, permite uma reconfiguração nas ações } \\
\text { individuais e coletivas no sistema ambiental. }\end{array}$ \\
\hline Cidadania ambiental & $\begin{array}{l}\text { O material; se utilizado pontualmente; ou seja, sem estar } \\
\text { vinculado a uma ação mais abrangente de EA, não apresenta } \\
\text { capacidade suficiente para promover uma discussão à cerca do } \\
\text { resgate dos direitos humanos e de todas as formas de vida, } \\
\text { nem sobre a configuração de uma nova ética social sobre o } \\
\text { meio ambiente. Se o mesmo for utilizado de forma introdutória } \\
\text { em ações socioambientais educativas ou de capacitação, este } \\
\text { pode elucidar pontos chave para se adentrar em discussões } \\
\text { mais profundas como as que cercam a cidadania ambiental, } \\
\text { embora seja necessário um trabalho contínuo no espaço-tempo } \\
\text { para que se alcance tal etapa do percurso. }\end{array}$ \\
\hline
\end{tabular}

Fonte: Kitzmann (2015).

Já a relação de compatibilidade do material produzido com a Educomunicação Socioambiental foi analisada por meio de seus princípios básicos. O primeiro deles é o compromisso com o diálogo permanente e continuado, o qual diz respeito à inclusão de atores e perspectivas com valorização de experiências acumuladas, novos modos de ver e novas formas de fazer e a uma ação constantemente recíproca entre governo e sociedade 
em âmbito de políticas públicas (COSTA, 2008). Neste sentido, o processo de produção do material se aproxima desse princípio ao passo que foi exatamente através das relações dialógicas entre professores, gestores, pesquisadores e artistas (e das respectivas trocas de experiências acumuladas) que os vídeos e cartilhas foram produzidos. O diálogo entre os componentes da equipe de trabalho possibilitou a composição de uma 'nova' forma de fazer Educação Ambiental costeira por meio da transposição de informações sobre a ZC e sua gestão de uma esfera do saber à outra. Da mesma forma, também pode ser considerado uma ação mútua entre o órgão governamental (MMA) e uma parcela da sociedade; a partir do fato que incorpora instituições públicas de ensino e o setor privado de produção audiovisual na composição do trabalho (STAUDT; MAZZARINO, 2016; BRAZ et. al., 2016).

Referente ao segundo princípio (compromisso com a interatividade e produção participativa dos conteúdos) pode-se analisar sua relação de compatibilidade por dois vieses. Primeiramente, o material é compatível com o mesmo por ter contado com a participação de profissionais diversos, além do setor governamental, para a sua concepção e produção. Porém, em segunda análise, a produção dos vídeos não foi aberta à participação de uma porção mais diversa da sociedade civil e, devido a isso, se torna incompatível com tal princípio. Contudo, é importante salientar que a intenção de uso do material é, também, proporcionar a interatividade entre diferentes atores sociais e com isso incentivar a construção de diálogos em torno dos temas abordados por ele em ações de EA (FunBEA, 2018).

No que tange ao terceiro princípio (compromisso com a transversalidade), o material produzido é congruente com o mesmo, pois tratou de ambos os temas com uma visão holística; abordando fatores ecológicos, sociais, econômicos e políticos e adotando a transversalidade que os assuntos abarcam. Além disso, a transversalidade na comunicação é retratada pela ampla divulgação do material, disponível em canais de plataformas de comunicação digitais, em programas de televisão, eventos ambientais e em redes sociais, tornando eficaz a canalização e difusão das informações socioambientais costeiras abordadas.

O compromisso com o diálogo de saberes é abordado pelo quarto princípio da Educomunicação Socioambiental e tem a ver com a promoção e valorização da união e do contato entre diferentes atores. Sempre fortalecidos pela ação dialógica, este é um fundamento metodológico para quaisquer práticas de Educomunicação (COSTA, 2008). E, neste sentido, o material apresenta uma junção de ideias de diferentes atores sociais por ter sido concebido e produzido por educadores e educadoras ambientais oriundos de distintas instituições, por pesquisadores de diferentes idades e visões sobre o tema, e, portanto, pode ser considerado compatível com este princípio, já que foi efetuado através de uma aliança de saberes (FRANÇA et. al., 2019).

Relativo ao quinto princípio (compromisso com proteção e valorização do conhecimento tradicional e popular), o material produzido diverge de tal 
princípio por apresentar uma lacuna em não incluir atores de comunidades costeiras que possuem conhecimentos tradicionais no processo de produção dos materiais. Neste caso, as informações utilizadas na composição dos vídeos foram baseadas em conhecimentos técnico-científicos e não em conhecimentos culturais indígenas e de comunidades tradicionais costeiras. Mas, ainda assim, o material favorece, devido à sua linguagem difusa e lúcida, a apropriação dos temas tratados por estes atores sociais.

Em relação ao sexto princípio da Educomunicação Socioambiental (compromisso com a democratização da comunicação e com a acessibilidade à informação), pode-se considerar que o material foi desenvolvido de uma forma democrática por um coletivo de diferentes profissionais atuantes na área da gestão ambiental costeira, Educação Ambiental , bem como na área de produção artística, o que possibilitou o acesso de todos os participantes aos meios de produção e sua gestão participativa, com o objetivo final de democratizar as informações socioambientais costeiras aos diversos atores. Todavia, é relevante apontar que, mesmo contando com a autonomia do coletivo na produção do material, este coletivo é composto por profissionais especializados em suas áreas de atuação, mas que atuaram parcialmente subordinados ao órgão governamental (MMA), o qual demandou os vídeos produzidos. Dessa forma, apresenta-se uma dicotomia, pois os materiais se configuram como uma produção "democrática" de ferramentas educomunicativas, porém subordinadas a um agente do governo federal. A dificuldade em democratizar o acesso à produção e à sua gestão também está presente nas referências supramencionadas nesta análise, mesmo que de forma implícita.

Referente ao penúltimo princípio (compromisso com o direito à comunicação) fez-se, através da produção das ferramentas abordadas, valer este direito, pois além da atuação profissional em áreas específicas do conhecimento, a equipe também atua através da comunicação, na tentativa de estabelecer uma ponte entre o conhecimento produzido na esfera acadêmica e um conhecimento possível de ser compreendido e adotado cotidianamente, contribuindo para que mais cidadãos tenham acesso a informações socioambientais e à comunicação.

Finalmente, em relação ao último princípio (compromisso com a não discriminação e o respeito à individualidade e diversidade humana), o material é confluente com o mesmo à medida que possui uma linguagem difusa e de fácil compreensão, que respeita a diversidade e singularidade humanas, não sendo discriminatória em nenhum sentido.

Com base nas argumentações apresentadas, é possível considerar os vídeos, de uma forma geral, compatíveis com os princípios regentes da Educomunicação Socioambiental. Apesar de haver certo distanciamento ideológico em alguns aspectos, como no segundo e no quinto princípio, ainda assim o material se comporta de maneira convergente com os demais princípios, podendo ser considerado uma ferramenta de Educomunicação

Revista brasileira educação ambiental 
Socioambiental Costeira capaz de subsidiar ações de Educação Ambiental, capacitações de atores sociais diversos e uma fonte de informação de livre e fácil acesso e compreensão.

Ainda assim, cabe ressaltar que o material produzido não contém em si todos os atributos para ser considerado um exemplo exímio de Educomunicação, pois não contou com uma ampla democratização social em sua construção e sua gestão também está restrita a um grupo de indivíduos, da mesma forma que sua realização partiu de uma necessidade governamental e não da necessidade de comunicação das comunidades costeiras sobre temas relevantes para elas (SCHAUN, 2002).

Deve-se destacar ainda, a potencialidade do material analisado na formação do Educomunicador Socioambiental, uma vez que o mesmo favorece o desenvolvimento de habilidades comunicativas voltadas para o fortalecimento de capacidades expressivas e formação cidadã. Tal característica favorece o desenvolvimento da capacidade de leitura crítica dos fenômenos e dos conteúdos e, por fim, auxilia na promoção da atuação conectada de educadores e comunicadores ambientais em processos de intercâmbio de conhecimentos, baseados no interesse comum e solidário (SOARES, 2011).

Portanto, os vídeos podem ser vistos não apenas como um meio de comunicação entre o governo, professores/pesquisadores e a sociedade, mas como uma ferramenta informacional - se utilizada individualmente - e como uma ferramenta de Educação Ambiental Costeira quando utilizada como material de apoio em ações de EA, podendo contribuir com o diálogo entre atores do processo e cumprindo um papel comunicativo onde as trocas dialógicas favorecem a democratização das informações contidas na ferramenta e a construção de novos conhecimentos, valores e atitudes.

\section{Conclusões}

A construção de ferramentas como as aqui discutidas exemplifica como é possível planejar e desenvolver ações de $\mathrm{GCl}$ que incorporem princípios básicos, como o direito à educação, à informação e à comunicação. Ademais, tais ferramentas têm potencial para auxiliar no fortalecimento dos indicadores de maturidade e eficácia da $\mathrm{GCl}$, pois está baseada na integração de diversas políticas públicas (PNMA, PNGC, PNEA), seguindo estruturas normativas já existentes como diretrizes e incorporando a participação do órgão competente pela área costeira do país.

No que diz respeito ao âmbito científico, a experiência advinda com o desenvolvimento desse tipo de trabalho reaviva uma postura mais crítica acerca do papel social da academia. Visto que ela opera na sociedade, é imprescindível que a ciência cumpra alguns dos seus propósitos primordiais: democratizar as informações produzidas nos institutos de ensino e pesquisa do país, bem como contribuir para o desenvolvimento das bases de conhecimento da sociedade. Dessa forma, é possível chegar à formação de indivíduos 
ecologicamente, economicamente, politicamente e socialmente críticos, ou seja, cidadãos ambientais.

Ainda, pertinentes são os questionamentos acerca da necessidade de construção, no âmbito da Educação Ambiental, de uma política pública de Educomunicação Socioambiental, a qual considere todos os segmentos sociais como fontes fecundas de informação e conhecimento e que seja capaz de subsidiar a construção de redes educomunicativas entre as comunidades costeiras, podendo contribuir de forma efetiva para a $\mathrm{GCl}$, formando um elo de trocas de saberes ao longo da zona costeira brasileira.

Entretanto, para além da democratização das informações socioambientais, para que se atinja a verdadeira cidadania ambiental e, por conseguinte, uma gestão efetiva do espaço costeiro, é fundamental que sejam repensadas as bases do sistema educacional sobre as quais a sociedade está ancorada. Conforme Sarkar (2008) se forem consideradas os três tipos de sabedoria; 1) instintiva (ligada à sobrevivência, reprodução e manutenção da espécie); 2) intelectual (ligada a capacidade de raciocínio e análise e a formação crítica de pensamento) e 3) intuitiva (ligada à consciência e à sua expansão), percebe-se que as iniciativas educacionais contemporâneas ainda priorizam apenas o desenvolvimento intelectual e desconsideram a sabedoria intuitiva inata do ser humano, a qual desencadeia efetivamente os processos de sensibilização e cidadania ambiental (SARKAR, 2008).

Dessa forma, e em consonância com Capra (2012), Steiner (1995, 2005) e Freire $(1980,1986,1988)$ não há possibilidade de uma real sensibilização ambiental e, por consequência, a formação de cidadãos ambientais se não forem reformuladas as bases educacionais geralmente

reducionistas pragmáticas hoje vigentes. É preciso reconhecer os seres humanos como ecossistemas individuais capazes de se interconectarem e assim reconhecerem os demais; se sensibilizando consigo mesmo e depois com o externo, respeitando a si mesmo para poder respeitar o ambiente no qual estão inseridos.

\section{Agradecimentos}

Ao Conselho Nacional de Desenvolvimento Científico e Tecnológico (CNPq), pelo apoio financeiro à pesquisa.

\section{Referências}

ABNT. Associação Brasileira de Normas Técnicas. Classificação dos Resíduos Sólidos: ABNT NBR 10004, Rio de Janeiro, 2004. Disponível em: $<$ https://analiticaqmcresiduos.paginas.ufsc.br/files/2014/07/Nbr-10004-2004Classificacao-De-Residuos-Solidos.pdf > . Acesso em: 23 mar. 2017. 
ANDERSON, L. W., KRATHWOHL, D. R., AIRASIAN, P. W., CRUIKSHANK, K. A., MAYER, R.E., PINTRICH, P. R., RATHS, J., WITTROCK, M. C. A Taxonomy for Learning, Teaching, and Assessing: A revision of Bloom's Taxonomy of Educational Objectives. New York: Pearson, Allyn \& Bacon, 2001.

ANDRADE, J.; SCHERER, M. Decálogo da gestão costeira para Santa Catarina: avaliando a estrutura estadual para o desenvolvimento do Programa Estadual de Gerenciamento Costeiro. Desenvolvimento e Meio Ambiente, v.29, p.139-154, 2014.

ASMUS, M.L., NICOLODI, J.L., ANELLO, L.S., GIANUCA, K. The risk to lose ecosystem services due to climate change: A South American case. Ecological $\begin{array}{llll}\text { Engineering, } & \text { v.130, } & \text { n.1, } & \text { p.233-241, }\end{array}$ https://doi.org/10.1016/j.ecoleng.2017.12.030.

BARRAGÁN MUNÕZ, J. M. Medio Ambiente y Desarrollo en Áreas Litorales: introducción a la planificación y gestión integradas. Cádiz, Espanha: Universidad de Cádiz, Servicio de Publicaciones, 2003.

BARRAGÁN MUÑOZ, J. M. Manejo Costero Integrado y Política Pública en Iberoamérica: Un diagnóstico. Necesidad de Cambio. Cádiz, Espanha: Red IBERMAR (CYTED), 2010.

BARRAGÁN MUÑOZ, J. M. Política, gestão e litotal: Uma nova visão da Gestão Integrada de Áreas Litorais. Madrid, Espanha: Editorial Tébar Flores, S.L., 2016.

BLOOM, B. S.; ENGELHART, M. D.; FURST, E. J.; HILL, W. H.; KRATHWOHL, D. R. Taxonomy of Educational Objectives. The Classification of Educational Goals. New York: David McKay Co Inc., 1956.

BRASIL. Lei n. 12.305, de 2 de agosto de 2010. Institui a Política Nacional de Resíduos Sólidos; altera a Lei no 9.605, de 12 de fevereiro de 1998. Brasília: DOU de 03/08/2010. Disponível em: <http://www.planalto.gov.br/ccivil 03/ ato2007-2010/2010/lei/l12305.htm>. Acesso em: 01 jun. 2020.

BRAZ, J. M. S.; FOGLIATTO, M. S. S; MOREIRA, B. D. Educomunicação Socioambiental: Um estudo de seus pontos de intersecção. In: Intercom Sociedade Brasileira de Estudos Interdisciplinares da Comunicação, Anais do XVIII Congresso de Ciências da Comunicação na Região Centro-Oeste Goiânia, Goiás, 19 a 21 de maio, 2016.

CAPRA, F. O ponto de mutação: A Ciência, a Sociedade e a Cultura emergente. São Paulo: Editora Cultrix, 30. ed., 2012.

CARTER, R. The myth of dangerous human-caused climate change. In: AusIMM New Leaders' Conference, 2007.

CASTELLO, J. P.; KRUG, L. C. Introdução às Ciências do Mar. Pelotas: Editora Textos, 2015.

COE, J. M.; ROGERS, D. B. Marine debris: sources, impacts and solutions. New York: Springer, 1997. 
COSTA, F. A. M. (Org.). Educomunicação socioambiental: comunicação popular e educação. Brasília: Ministério do Meio Ambiente, 2008.

DELIZOICOV, D.; ANGOTTI, J. A.; PERNAMBUCO, M. M. C. A. Ensino de ciências: fundamentos e métodos. São Paulo: Cortez, 2002.

DEMAJOROVIC, J. Da política tradicional de tratamento do lixo a política de gestão de resíduos sólidos - As novas prioridades. Revista de Administração de Empresas, v. 35(3), p.88-93, 1995.

FRANÇA, F. F.; KATAOKA, A. M.; AFFONSO, A. L. S.; CRISOSTIMO, A. L. Educomunicação socioambiental: produção de peças educomunicativas como metodologia de ensino para a Educação Ambiental . Revista Práxis, v. 21(11), 2019.

FREIRE, P. Pedagogia do oprimido. Rio de Janeiro: Paz e Terra, 1975.

FREIRE, P. Conscientização: teoria e prática da libertação: uma introdução ao pensamento de Paulo Freire. São Paulo: Moraes, 1980.

FREIRE, P. Educação como prática da liberdade. Rio de Janeiro: Paz e Terra, 1986.

FREIRE, P. Educação e mudança. São Paulo: Paz e Terra, 1988.

FREITAS, V. P.; FREITAS, G. P. Crimes contra a Natureza. São Paulo: Revista dos Tribunais, 6. ed., 2000.

FUNBEA. Fundo Brasileiro de Educação Ambiental. Educomunicação socioambiental e conservação de recursos hídricos. São Paulo. Ed. Diagrama. 2018.

GORMAN, D.; MOREIRA, F.; TURRA, A.; FONTANELLE, F. R.; COMBI, T.; BÍCEGO, M.; MARTINS, C. C. Organic contamination of beached plastic pellets in the South Atlantic: Risk assessments can benefit by considering spatial gradients. Chemosphere, v. 223, p. 608-615, 2019.

HOEFEL, F. G. Morfodinâmica de praias arenosas oceânicas: uma revisão bibliográfica. Itajaí: Editora da UNIVALI, 1. ed., 1999.

IMO. International Maritime Organization. Manual on Oil Pollution - Section II, Edition. 2018

IPCC. Intergovernmental Panel on Climate Change. Summary for Policymakers. In: Global Warming of $1.5^{\circ} \mathrm{C}$. An IPCC Special Report on the impacts of global warming of $1.5^{\circ} \mathrm{C}$ above pre-industrial levels and related global greenhouse gas emission pathways, in the context of strengthening the global response to the threat of climate change, sustainable development, and efforts to eradicate. In: Press, v. 1, 2018. Disponível em: $<$ https://www.ipcc.ch/site/assets/uploads/sites/2/2019/05/SR15 SPM version r eport LR.pdf> . Acesso em: 05 ago. 2019.

KAPLÚN, M. Una Pedagogia de la Comunicación. Madrid: Ediciones de la Torre, 1998. 
MANDEL, V. Comment développer une conscience écologique? La Recherche, v. 243(23), p. 664-666, 1992.

KITZMANN, D. I. S. Convergências e Percursos Formativos em Educação Ambiental. Anais do VI EDEA: Encontros e Diálogos com a Educação Ambiental. Rio Grande, 24 a 26 de set., 2015.

KOENE, J. Plastic Soup: Mapping the first steps towards solutions. Wageningen University Press, 2010.

LAVENDER, K. L.; MORÉT-FERGUSON, S.; MAXIMENKO, N. A.; PROSKUROWSKI, G.; PEACOCK, E. E.; HAFNER, J.; REDDY, C. M. Plastic Accumulation in the North Atlantic Subtropical Gyre. Science, v. 5996(329), p. 1185-1188, 2010.

MARENGO, J. A.; SCARANO, F. R.; KLEIN, A. F.; SOUZA, C. R. G.; CHOU, S. C. Impacto, vulnerabilidade e adaptação das cidades costeiras brasileiras às mudanças climáticas: Relatório Especial do Painel Brasileiro de Mudanças Climáticas. Rio de Janeiro: PBMC, COPPE - UFRJ, 2016.

MARQUES JR., A. N.; MORAES, R. B. C.; MAURAT, M. C. Poluição marinha. In: PEREIRA, R. C; SOARES-GOMES, A. (Orgs.). Biologia Marinha. Rio de Janeiro: Interciência, p. 505-528, 2009.

MENEZES, R. A. M.; Silva, E. C.; Costa, M. F. S.; Cunha, M. C. C.; Sarabia, M. L.; Silva, T. A.; Moura, G. J. B. Avaliação quali-quantitativa dos resíduos sólidos carreados para o reservatório do Tapacurá, Pernambuco, Brasil. Revista Ouricuri, v. 4, n. 1, p. 060-085, 2014.

MILANI, C. R. S. O princípio da participação social na gestão de políticas pública locais: uma análise de experiências latino-americanas e europeias. Revista de Administração Pública, v. 42(3), p. 551-579, 2008.

MORAES, S.; SABOYA, R.; ABIB, S.; REIS, M. J. Capacitação e Mobilização: a Perspectiva da Participação Cidadã no Plano Diretor de Balneário Camboriú (SC), Brasil. Journal of Integrated Coastal Zone Management, v. 10(4), p. 567-587, 2010.

MUEHE, D. Erosão Costeira - Tendência ou Eventos Extremos? O Litoral entre Rio de Janeiro e Cabo Frio, Brasil. Journal of Integrated Coastal Zone Management, v. 11, n.3, p. 315-325, 2011.

NAKANO, K. (Cord.). Projeto Orla: implementação em territórios com urbanização consolidada. São Paulo: Instituto Polis; Brasília: Ministério do Planejamento, Orçamento e Gestão, 2006.

NASCIMENTO, F. C.; LIMA, J. J. F. Diretrizes técnicas para locação de limites edificados em praias. Ambiente Construído, v. 10(4), p. 197-218, 2010.

NICOLODI, J. L., PETERMANN, R. M. 2010. Potential vulnerability of the Brazilian coastal zone in its environmental, social and technological aspects. Pan-American Journal of Aquatic Sciences, v. 5, p. 184-204. 
NICOLODI, J. L.; ASMUS, M.L.; TURRA, A.; POLLETE, M. Avaliação dos Zoneamentos Ecológico-Econômicos Costeiros (ZEEC) do Brasil: proposta metodológica. Desenvolvimento e meio ambiente, v. 44, p. 378-404, 2018.

NICOLODI, J.L.; ASMUS, M.L.; POLETTE, M.; TURRA, A.; SEIFERT, C.A.; STORI, F.T.; SHINODA, D.C.; MAZZER, A.; SOUZA, V.A.; GONÇALVES, R.K. Critical gaps in the implementation of Coastal Ecological and Economic Zoning persist after 30 years of the Brazilian coastal management policy. Marine Policy, v.128, 104470, 2021. https://doi.org/10.1016/j.marpol.2021.104470

ONU. Organização das Nações Unidas. Transformando Nosso Mundo: A Agenda 2030 para o desenvolvimento Sustentável. New York. 2015.

PNA. Plano Nacional de Adaptação à Mudança do Clima. Brasília: Ministério do Meio Ambiente. Volume I: Estratégia Geral, 2016. Disponível em: $<$ http://www.pbmc.coppe.ufri.br/documentos/PNA-Volume1.pdf> . Acesso em: 23 jul. 2017.

PNMC. Plano Nacional sobre Mudança do Clima. Brasília: Ministério do Meio Ambiente. Volume I, 2016. Disponível em: $<$ http://www.pbmc.coppe.ufri.br/documentos/PNA-Volume1.pdf> . Acesso em: 23 jul. 2017.

PORTO, G. E. L. Responsabilidade pela poluição marinha. Revista. CEJ, v. 12, p. 51-57, 2000.

QUINTAS, J.S.; GUALDA, M. J. A formação do educador para atuar no processo de Gestão Ambiental. Brasília: Edições IBAMA, 1995.

QUINTANA, C. G.; KITZMANN, D. I. S. Políticas Públicas na Educação Ambiental e as Mudanças Climáticas. Revista Brasileira de Política e Administração da Educação, v. 36, p. 336-356, 2020.

ROCKLOFF, S. F.; LOCKIE, S. Participatory tools for coastal zone management: use of stakeholder analysis and social mapping in Australia. Journal of Coastal Conservation, v. 10, p. 81-92, 2004.

SABEDOT, S. Os processos geológicos e as alterações climáticas. Diálogo, $v$. 13, p. 157-171, 2008.

SANTOS, M. S. T.; AMARO, V. E.; FERREIRA, A. T. S.; BARBOZA, A. A.; FIGUEIREDO, M. C.; ARAÚJO, A. G. Metodologia para mapeamentos de vulnerabilidade costeira à elevação do nível médio do mar (NMM) em escala local. BCG - Boletim de Ciências Geodésicas, v. 21, n.4, p. 691-705, 2015.

SARKAR, P. R. Ideia e Ideologia. Brasília: Editora Ananda Marga, 2008.

SCHAUN, A. Educomunicação: Reflexões e Princípios. Rio de Janeiro: Mauad, 2002.

SCHIVELY, C. A. Quantitative Analysis of Consensus Building in Local Environmental Review. Jounal of Planning Education and Research, v. 27, p. 82-98, 2007. 
SKINNER, B. J.; PORTER, S. C. The dynamic earth: an introduction to physical geology. New York: John Wilry \& Sons, 5. ed., 2004.

SNYDERS, G. A alegria na escola. São Paulo: Manole, 1988.

SOARES, I. O. Educomunicação o conceito, o profissional, a aplicação: contribuições para a reforma do Ensino Médio. São Paulo: Paulinas, ed., 2011.

SOMMERVILLE, S. E.; MILLER, K. L., MAIR, J. M. Assessment of the aesthetic quality of a selection of beaches in the Firth of Forth, Scotland. Marine Pollution Bulletin, v. 46, n.9, p. 1184-1190, 2003.

SOUZA, C. A nova gestão pública. In: MACHADO, G.; PINHO, A.; SOUZA, C.; PASSOS, E.; VALENTE, A. Gestão pública: desafios e perspectivas. Salvador: Fundação Luís Eduardo Magalhães, p. 38-62, 2001.

STAUDT, M. V.; MAZZARINO, J. M. Dispositivos audiovisuais na educomunicação socioambiental escolar: Explorações políticas e estéticas. Revista Brasileira de Educação Ambiental , v. 11(1), p. 157-172, 2016.

STEINER, R. A arte da educação I: o estudo geral do homem, uma base para a pedagogia. São Paulo: Antroposófica, 1995.

STEINER, R. A arte de educar baseada na compreensão do ser humano. São Paulo: Federação das Escolas Waldorf no Brasil, 2005.

STROHAECKER, T. M. Dinâmica populacional. In. NICOLODI, J.L., ZAMBONI, A. (Eds.). Macrodiagnóstico da Zona Costeira e Marinha do Brasil. Brasília, DF: Ministério do Meio Ambiente, 2008.

STOMMEL, H. M.; MOORE, D. W. An introduction to the Coriolis force. Columbia University Press, 1989.

TANNER, R.T. Educação Ambiental. São Paulo: Summus/Edusp, 1978.

TASSARA, E. Dicionário Socioambiental: idéias, definições e conceitos. São Paulo: FAART, 2008.

TOL, R. S. J. The Economic Impacts of Climate Change, Review of Environmental Economics and Policy, v. 12, n.1, p.4-25, 2018.

UNEP. United Nations Environment Programme. Marine plastic debris and microplastics - Global lessons and research to inspire action and guide policy change. Nairobi, 2016. Disponível em: < https://wedocs.unep.org/handle/20.500.11822/7720> . Acesso: 12 out. 2017.

UNEP. United Nations Environment Programme / Intergovernmental Oceanographic Commission. Guidelines on Survey and Monitoring of Marine Litter. Regional Seas Reports and Studies, IOC Technical Series, $83.2009 . \quad$ Disponível em: $<$ https://wedocs.unep.org/bitstream/handle/20.500.11822/13604/rsrs186.pdf?se quence $=1$ andisAllowed $=\mathrm{y}>$. Acesso em: $18 \mathrm{abr}$. 2017.

WATTS N, NEIL, A. W.; AGNOLUCCI P. et al. Health and climate change: policy responses to protect public health. Lancet, v. 386, p. 1861-1914, 2015. 